\title{
Rules Governing Presidential Primaries
}

\author{
John G. Geer \\ Arizona State University
}

Many observers of American politics have been highly critical of the proliferation of primaries that occurred in the 1970s. One of the reasons given for this unfavorable assessment is that the direct primary cannot consistently yield candidates who have broad electoral support-something that is thought necessary to win general elections. And since the major goal of parties is to win elections, this perceived shortcoming is cause for concern.

In this article I show, however, that the problem lies not with the direct primary itself, but rather with the rules that govern presidential primaries. In fact, if parties would allocate delegates proportionally to candidates, adopt a preference ballot, and allow independents and "swing" voters to participate, the direct primary would offer an excellent opportunty to nominate candidates with broad support.

$\mathbf{O}_{\text {ne }}$

e of the fundamental tenets of American politics is that political parties strive to win elections. From M. Ostrogorski's (1902) investigation of how American parties actually work to Anthony Down's (1957) analysis of how parties ought to behave, this belief has served as the anchor of much of the best discussion of party politics that we have. Yet many scholars claim that the replacement of a politician-dominated system of presidential nominations with one dominated by rank-and-file voters has weakened the capacity of the national parties to nominate candidates with broad electoral support-something that is generally thought necessary to win general elections. Perhaps for this reason, many of the most prominent scholars of political parties have been skeptical, if not openly hostile, to the new system of nominations, viewing them as antithetical to the fundamental purposes of parties (Ceasar, 1979, 1982; Polsby, 1983; Ranney, 1975).

Few can doubt that direct primaries remove power from party professionals and give it to voters. But it does not follow that primaries prevent parties from nominating candidates that increase the party's chance for success in November. My aim in this paper is to argue that

-For thoughtful comments and assistance I would like to thank James D. DeNardo, Stanley Kelley, Jr., Thomas R. Rochon, and the anonymous referees of this journal. A special note of thanks goes to John Zaller, whose help was invaluable in the completion of this study. As always, I bear sole responsibility for the analyses and interpretations presented here. 
the proliferation of primaries represents no particular threat to the capacity of parties to nominate candidates with broad support. For although it is true that party leaders can no longer meet and bargain to choose candidates directly, it remains within their power to make the rules by which candidates are chosen. This power is sufficient to their needs. A well-designed system of primaries can, at a minimum, do a better job of selecting popular candidates than the current system, and may arguably do as well as the much-lauded "mixed" system.

The reason that primaries can select candidates with broad support is that these contests provide an opportunity to measure voters' preferences for candidates. In the "mixed" system, party leaders sought to pick the most electable candidate available. They accomplished this by guessing which candidates voters would be most likely to support in November. Presidential primaries, in contrast, can actually test a candidate's popularity, and hence his electability. As Nelson Polsby (1960) once observed, presidential primaries can serve "as a means by which politicians inform themselves about the relative popularity of presidential aspirants" (p. 617).

The problem, however, is that a system of primaries does not automatically produce nominees who are capable of doing well in the November election. Factional candidates may skillfully parlay narrow but intense support into a party nomination, or party regulars, who lack appeal to independents, may sweep to victory. Consequently, the rules for primaries must be designed in such a way that the candidate who receives the most delegates (and hence, presumably the nomination) will be a candidate with broad appeal.

In this paper, I shall propose three sets of changes in the rules governing presidential primaries that would bring about this desirable result. First, delegates should be allocated in proportion to a candidate's share of the vote. Second, the balloting system in primaries should be altered to permit voters to express the intensity of their preferences. Finally, it should be easier for independents and weak partisans of the opposing party to vote in the primary of their choice. By implementing these changes, primaries would consistently yield nominees with broad electoral appeal. ${ }^{1}$

\section{Votes AND Delegates}

Since primary voters do not directly decide who will be the nominee but instead select delegates who actually choose nominees, it is important to know how their votes translate into delegates. Different systems of

\footnotetext{
${ }^{1}$ There are other possible rules one might want to address in seeking to improve our current system of presidential selection generally, such as New Hampshire's role as the nation's first primary. While these other rules are important, I am setting aside such concerns and only focusing on whether primaries per se can yield candidates with broad support.
} 
allocation affect the number of delegates a candidate receives and hence affect how the preferences of voters are registered. If we want the allocation of delegates to reflect accurately the popularity of candidates, then we want a system that does not skew the results in favor of particular candidates by magnifying the size of their victory (or loss).

There have been four basic allocation systems: proportional representation, winner-take-more, winner-take-all, and "loophole." A state using proportional representation allocates delegates among candidates in proportion to their share of the vote. The winner-take-more system, adopted for the Democratic contest in 1984, allocates delegates to candidates by congressional district in proportion to their share of the vote, but the winner of the district receives a bonus delegate. The winnertake-all system gives all the state's delegates to the candidate who receives the most votes statewide. A "loophole" primary is winner-take-all by congressional district. ${ }^{2}$

One way to examine how different allocation systems might affect how votes are recorded is to see if different schemes would have changed the proportion of delegates a candidate received in past contests. ${ }^{3}$ Lengle and Shafer (1976) argue that in the 1972 race for the presidential nomination "the beneficiary of the power hidden in the rules of the game was Senator George McGovern. Most primaries offered by (congressional) District and Districted primaries maximized McGovern's strength. One simple shift, however, to generalized Winner-Take-All laws would have minimized that strength, in the process guiding a healthy plurality of delegates (along with the nomination?) to Senator Hubert Humphrey. A second change, to proportional representation, would have undercut both McGovern and Humphrey, leaving only Governor George Wallace to derive electoral satisfaction from primary rules" (p. 25).4 This argument assumes that under different rules the actions of McGovern (and other candidates) would have been the same. Behavior of candidates, however, "cannot be expected to be constant under different institutional arrangements" (David and Ceasar, 1980, p. 36). If for example, all states were winnertake-all, candidates might target resources in those states in which they had a chance, while in a system of proportional representation, candidates

\footnotetext{
2 This classification does not take account of all the variations in the rules for primaries, since individual states often introduce slight differences. For example, the minimum share of the vote necessary to qualify for delegates often varies between states. David and Ceasar (1980) note that "despite the increased standardization in selection procedure that has taken place over the past decade (especially in the Democratic party), each state nomination race remains in many respects unique, colored by its own laws, party rules, traditions and political culture." Nonetheless, my four categories encompass the major differences.

${ }^{3}$ See Lengle and Shafer (1976); Hammond (1980); Gerald Pomper (1979); and David and Caesar (1980).

${ }^{4}$ Hammond (1980), however, disagrees with Lengle and Shafer's conclusion. He argues they used biased data because they excluded the cases of California and New Mexico.
} 
would be more likely to enter all contests, since even a small proportion of the vote could yield a few delegates. In what follows, I shall not speculate about how the different rules might have changed outcomes; instead I shall show how the candidates fared under each system and to what degree different rules affect the allocation of delegates and hence how voters' preferences were registered.

Edward Tufte (1973) has suggested a useful way to examine how different rules affect the translation of votes into delegates. In studying ,the relationship between seats and votes in legislative contests, Tufte posits a simple linear model:

$$
\mathrm{Y}=\mathrm{A}+\mathrm{Bl}(\mathrm{X})+\mathrm{E}
$$

where $\mathrm{Y}$ is the percentage of seats for a particular party and $\mathrm{X}$ is the percentage of votes for that party. One can adapt this equation to the issue at hand, by making $Y$ the percentage of delegates for a candidate and $\mathrm{X}$ the percentage of votes for that candidate. This linear equation, so modified, yields three politically meaningful numbers which can be compared over time, between parties, between candidates and between allocation systems. The first is the regression slope or what Tufte calls the "swing ratio" or "responsiveness." If the swing ratio is 2 , that means for every $1 \%$ change in the vote there is a $2 \%$ change in the proportion of delegates awarded a given candidate. The second is the "bias," which measures the percentage of votes necessary to receive $50 \%$ of the delegates. These two numbers provide information on how well the various systems translate votes (i.e., preferences) into delegates and the extent to which certain candidates were helped or hurt by the rules. The third measure, which I shall term the "threshold" (the x-intercept of the regression line), shows the percentage of votes necessary to receive any delegates at all. The threshold figure is important to candidates such as Jesse Jackson, who want, perhaps for bargaining purposes, to stay in the presidential race to the convention even though they have no chance of winning the nomination themselves.

While the linear equation provides useful indicators of how well preferences are being recorded, a potential problem arises when the relationship between the share of delegates and the share of the vote is not strictly linear. A small proportion of the vote may yield no delegates, while a large proportion of the vote may bring an even bigger proportion of delegates than the vote share indicates. Systems other than proportional representation provide the winner of the primary more delegates than his proportion of the vote indicates. ${ }^{5}$ If the relationship is not linear, then the

\footnotetext{
${ }^{5}$ This statement is not strictly accurate. Since most proportional systems require that candidates receive at least some share of the vote to be eligible for delegates, candidates with a small electoral basis often gain no delegates.
} 
regression results may yield biased estimates. ${ }^{6}$ If one plots the proportion of delegates by the proportion of votes, however, the relationship for most years is quite linear. The Democratic contest in 1972 is the only notable exception, so the problem does not appear to be a major one.

A system of allocation would record votes accurately if candidates were awarded delegates in strict proportion to their shares of the primary vote; that is, the responsiveness would be 1 with a bias of $50 \%$ and a threshold of $0 \% .{ }^{7}$ No system in actual use is likely to measure the preferences of voters so accurately. As Tufte (1973) argues, "arrangements for translating votes into legislative seats almost always work to benefit the party winning the largest share of the votes" (p. 540). ${ }^{8}$ Nevertheless, this ideal outcome provides a benchmark by which to judge the different systems and how candidates profited from various ways of apportioning delegates.

Table 1 reports the responsiveness, bias, threshold and linear fit (Rsquared) of delegate allocation from 1972 to 1984 . In 1972 Senator McGovern benefited from the rules of the Democratic Party, as Lengle and Shafer (1976) suggested. McGovern typically needed only about 31\% of the vote to receive $50 \%$ of the delegates, while Senator Humphrey needed about $50 \%$ and Governor Wallace about $40 \%$ of the vote to secure half of the delegates. The slope tells a similar story-McGovern typically received $2.3 \%$ of the delegates for each $1 \%$ increase in votes. Humphrey's responsiveness was 1.33, about 40\% lower than McGovern's.

In 1976 the Democratic rules reflected the candidates' share of the vote more accurately than in 1972 . The slope when using all cases declines from 1.92 to 1.23 , and the bias is $43.1 \%$ in 1976 compared with $37.7 \%$ in 1972 . This change is due to the increased number of states using proportional representation in 1976. The responsiveness for proportional representation is almost 1 to 1 , while in loophole contests it is almost 2 to 1 .

The Republican contests in 1976 were relatively unbiased, but the slopes were high. The slope is 2 for all cases, and this figure rises to 3.36 when one examines only loophole states. While President Ford benefited from the rules, he did so to a lesser degree than did McGovern in 1972. The

\footnotetext{
${ }^{6}$ Tufte (1973) notes this problem and examines two nonlinear fits-the "cube law" and a logit model. He concludes that while the logistic fit was "statistically more satisfactory than the linear fit . . . its coefficients are not as readily interpretable from a political point of view as those of the linear model" (p. 547). I also tried both nonlinear fits for a number of years and concluded they were not so useful as the linear model.

${ }^{7}$ Note that the bias and threshold are directly related to each other, since they both are a product of the $x$-intercept. I report them separately because they are useful indicators in assessing the allocation rules.

${ }^{8}$ Rae (1967) and Lakeman (1970) concur with Tufte (1973) that the winner's share of legislative seats is often exaggerated because of electoral laws, especially the "first past the post" system.
} 


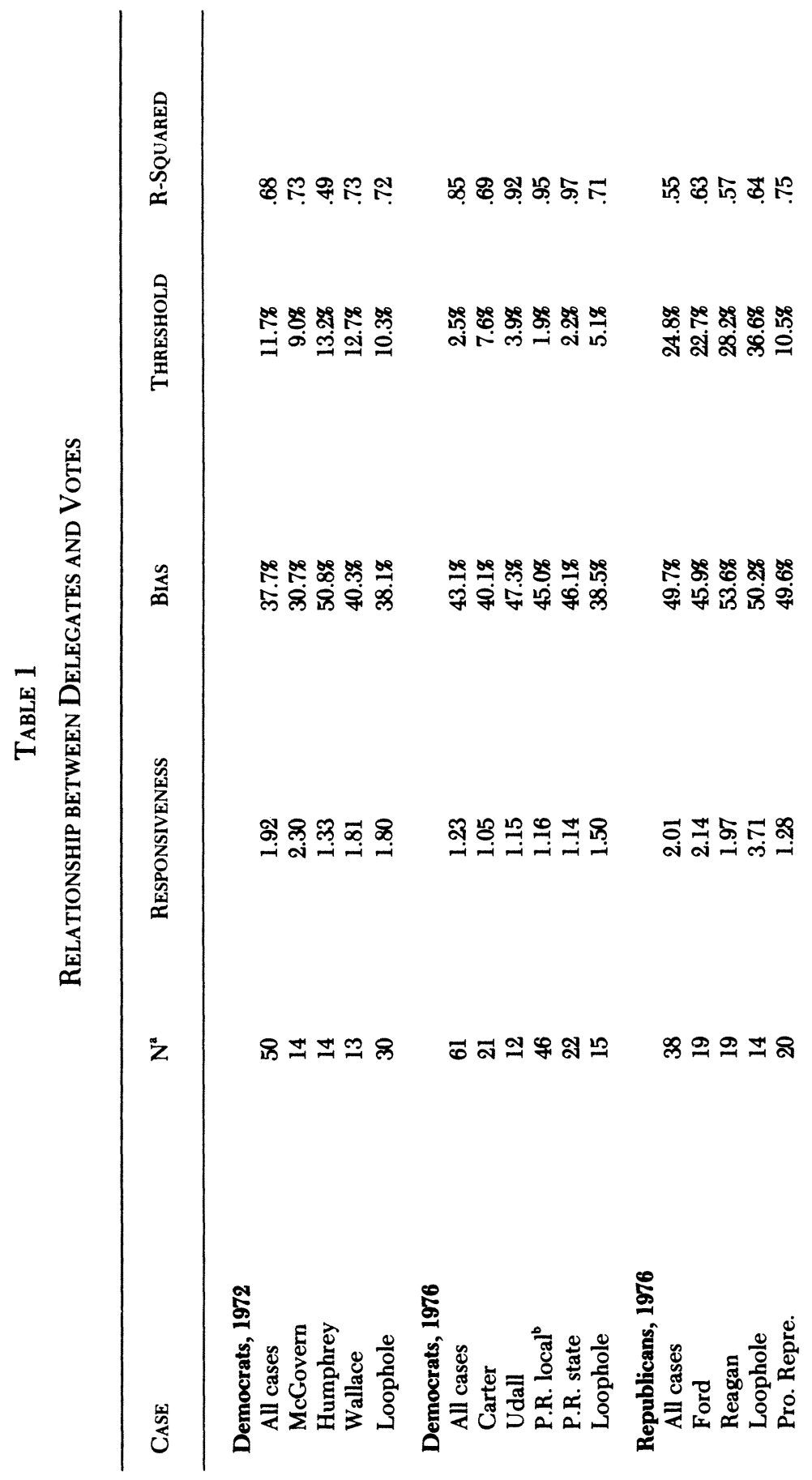




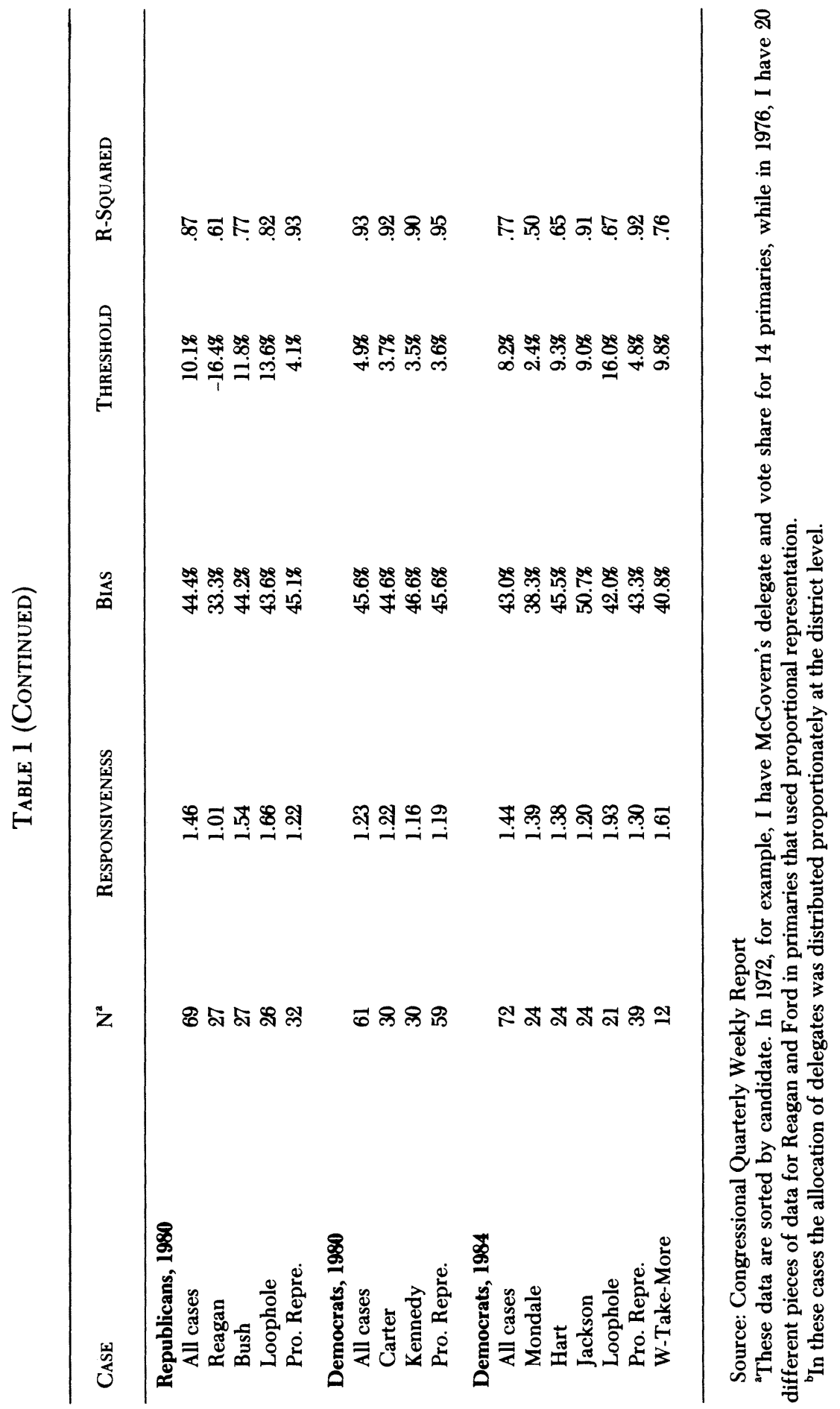


responsiveness of the system of delegate apportionment slightly favored Ford over Governor Reagan. In 1980 Reagan was able to turn the tables partially. He had a very favorable bias- $33 \%$ of the vote gave him $50 \%$ of the delegates. George Bush, however, had a more favorable translation of votes into delegates-1.54 to 1.01. As with the Democrats, the states using proportional representation came closer to an accurate reflection of the vote.

The rules for the 1980 Democratic nomination contest produced the most accurate system so far: responsiveness was 1.23 , bias $45.6 \%$, and threshold 4.9\%. The reason for these results is that almost all states employed a proportional representation system in that year. There was also little difference in swing ratio or bias between President Carter and Senator Kennedy: Carter's swing ratio was 1.22, while Kennedy's was 1.16, while the bias suggests only a slight edge to Carter-44.6\% to $46.6 \%$.

The rules governing the 1984 Democratic nomination contest benefited Walter Mondale, as the former vice-president's strategists intended. He typically needed about $38 \%$ of the vote to receive $50 \%$ of the delegates. The swing ratio for Mondale was 1.39, a figure similar to that for Senator Hart, but larger than that for Jackson (1.2). Jackson also generally needed more votes than either of his rivals to receive $50 \%$ of the delegates. As in other years, the proportional representation system produced the results that best reflected the candidates' share of the vote, with the loophole systems doing the worst job. ${ }^{9}$

During the 1984 pre-nomination campaign, Jesse Jackson complained that the system of delegate apportionment treated him unfairly. ${ }^{10}$ His complaints are clearly warranted. Compared with Mondale, Jackson had a higher threshold, lower responsiveness, and a less favorable bias. $\mathrm{He}$ was not, however, the most disadvantaged candidate in recent years; that dubious honor goes to Humphrey.

Allocating delegates in proportion to a candidate's share of the vote is clearly the best way for primaries to record the preferences of voters accurately." In states that used proportional representation, the fraction of the delegates awarded a candidate roughly reflects his or her fraction of the vote, while the other rules skew the results. Parties often write the rules, however, to favor particular candidates. It is difficult to separate the "feelings about changes in the rules from their [the rule makers] policy and candidate preferences" (Ranney, 1975, p. 144). The purpose of the

${ }^{9}$ As a side note, while the rules governing the primary contests from 1972 to 1984 introduced bias into the allocation of delegates, the primary rules appear "fairer" than the electoral systems Tufte (1973) examined.

${ }^{10}$ See the New York Times on April 24, May 11, and May 24 of 1984 for articles reporting Jackson's complaints.

${ }^{11}$ Rae (1967) and Lakeman (1970) reached similar conclusions when examining how election laws affect the votes-to-seat ratio. 
1984 rules, for example, was to diminish the chances of outsiders and enhance the odds favoring Mondale and Kennedy. But if the parties want to have a more accurate reading of a candidate's popularity to register at the time of the convention, then proportional representation should be adopted.

\section{THE BALLOT}

Some would argue that primaries, regardless of the rules governing the allocation of delegates, cannot measure preferences of voters very well. John Kellet and Kenneth Mott (1977) argue: "The primaries force a choice upon the voters. From an often large field of contenders, we are allowed to support only one. In cases where several candidates may espouse similar views and attract the same followers, the voters must divide their support among them, making it possible for a less popular person to win" (p. 529). Nelson Polsby (1983) expands on this assessment: "Second choice candidates enjoying widespread approval are unable to get into a game in which only first choices are counted. This becomes a problem because all first choice candidates of some voters are minimally acceptable to other voters-conceivably even to large numbers of voters to whom the party wants to appeal in the general election" (p. 165). These criticisms are justified. In a large field of candidates, a contender can often win a primary with 30 to 40 percent of the vote. Yet 60 to 70 percent of voters may not support-or may even greatly dislike-the candidate who wins the primary. ${ }^{12}$ This criticism, however, questions the desirability of allowing only first preferences to be expressed, not the direct primary. As Duncan Black (1958) argued, "The effect of the single vote is to suppress evidence of all preferences felt by the voter except his first preferences for a single candidate" (p. 62). In this section, therefore, I shall argue that the preference ballot should replace the current ballot, since it offers the best way for primaries to measure accurately the preferences of voters for candidates. ${ }^{13}$

The preference ballot, or the "alternative vote," allows each voter to rank candidates from first to last choice.${ }^{14}$ If no candidate wins a majority

${ }^{12}$ Numerous studies document this problem. See Duncan Black (195B), Lakeman (1970), Polsby (1983), Dennis Mueller (1979), Brams and Fishburn (1983), and Joslyn (1976).

${ }^{13}$ Of course, a commonly discussed alternative to first preference voting is Approval Voting. A number of scholars have supported such a system. See Brams and Fishburn (1983), Kellet and Mott (1977), DeMaio and Muzzio (1981), and Joslyn (1976). Approval voting, however, does not allow voters to indicate their intensity of preference, only the range of their preference. Consequently, this ballot provides less information about voters' preferences than preference voting. Moreover, strategic concerns may enter into voters' decisions. See Niemi (1984) and Niemi and Bartels (1984) for intelligent discussions of this weakness of approval voting.

${ }^{14}$ See Lakeman (1970) for an account of the alternative vote, chapter 3. 
of first-place votes, then the candidate finishing last is dropped and his or her supporters go to their second preference. The elimination of candidates continues until a candidate receives a majority of votes. Under this system voters explicitly list their preferences, allowing parties to identify the second and third choices of the electorate. Consequently, candidates with only a small but intense following would not be able to win a primary. Only those candidates with broad support could winan outcome that bodes well for the party in general elections.

Some argue, however, that preference voting poses problems that make it an unattractive alternative. One criticism of preference voting is that the plurality winner could be eliminated after a series of vote transfers, upsetting that candidate's supporters and making party unity difficult. Second, the candidate who is most acceptable may not be chosen, because that candidate finished a close last and hence was eliminated (Brams and Fishburn, 1983).

The first criticism is a hybrid of correct and incorrect claims. It is true that preference voting could eliminate potential plurality winners-but only if the plurality winners had little or no support outside their narrow circle of voters. Thus, George McGovern, the plurality winner in 1972, probably could not have been nominated in 1972 because many of the 70 percent of primary voters that did not vote for him that year strongly disliked him. But the elimination of plurality winners with narrow bases of support would not hamper party unity; it would, in all probability, make it easier by ensuring that whoever did win the nomination would have broad support within the party.

Moreover, one must remember that the main purpose of preference voting is to secure candidates who are minimally acceptable to the entire electorate. That means preventing intense but extreme minorities from putting their first choice over on unwilling majorities. Critics who object to this feature of the preference ballot are thus claiming, in effect, that the feelings of intense minorities are more important than those of majorities. Whatever may be said for that position on normative grounds, it is not one that is well calculated for coalition-building and winning general elections.

This criticism also incorrectly assumes that plurality winners necessarily represent the feelings of intense minorities. In some cases, a plurality winner may emerge only because of the particular field of candidates. For example, one liberal in a field of a half a dozen moderates is likely to emerge as a plurality winner even though any of several moderates might have much broader appeal in the party. That preference voting would prevent such plurality victories is its strength rather than its weakness.

The second criticism does identify a potential problem for the preference system. In a multi-candidate race, the elimination of the 
candidate with the fewest first-place votes could result in the elimination of the candidate with the broadest support. Brams and Fishburn (1983) cite the Senate race in New York in 1970 as an example. In that race, James Buckley, Richard Ottinger and Charles Goodell sought the Senate seat. Under a system of preference voting, Goodell would have been eliminated since he finished last in the race. Conceivably, however, he might have beaten either Buckley or Ottinger in a two-candidate contest. Such situations, however, are not common in primaries. In multi-candidate primaries, the last-place finisher is generally a weak candidate with little support. In 1984, after the initial contests, Jesse Jackson generally finished last. He was a factional candidate with considerably less support than Hart and Mondale. In many struggles for the nomination, the number of candidates has been quite large-such as in 1972, 1976, and 1984 for the Democrats, and in 1980 for the Republicans. But many of these candidates who finished last have had only a small following and thus were not competitive with the front-runners. Such names as Fred Harris, Reubin Askew, and Birch Bayh spring to mind.

A major advantage of preference voting is that strategic voting is discouraged (Lakeman, 1970, p. 71-3). "First preference" voting creates incentives for voters to consider the chances of candidates to win as well as their true preferences. When explicitly ranking preferences, however, voters need not worry about wasting a vote, since their second choice counts if their first choice is eliminated.

Another advantage of preference voting is that it asks voters to think in terms they are well accustomed to. Voters can easily rank preferences and often do so. When confronted with a series of options, people often rank them: "I'd rather visit my parents than go shopping, but I do not want to watch television." Since voters have preferences, we should ask them, and by so doing obtain better information about their preferences.

At this point, I have advocated two reforms for presidential primariesallocate delegates to candidates in proportion to their share of the vote and adopt a preference ballot. Under these two changes, if one candidate receives $50 \%$ or more first-place votes, the delegates would be allocated proportionally to all contenders. But if no candidate won at least $50 \%$ of the vote, a likely possibility in early primaries, then the last-place finisher would be eliminated and that candidate's supporters would be given to their second preference. This process would continue until one candidate has $50 \%$ of the vote. At that point, delegates would be allocated proportionally to the remaining candidates. ${ }^{15}$ These reforms would prevent candidates with narrow bases of support from winning primaries, because a candidate must have at least some degree of support from $50 \%$ of the electorate to win a primary. And at the same time, the proportional representation rule assures that all "serious" candidates win a share of the delegates commensurate with their share of the vote. Consequently, the 
combination of these two rules should allow for an accurate assessment of the breadth of a candidate's support-a goal that was central to the nomination of candidates in the "mixed" system.

\section{Who Should Vote in Presidential Primaries?}

While determining the breadth of support for a candidate is important to selecting electable nominees, we must now decide whose support should be measured by primaries. This question requires us to decide who should be considered "party members." Such decisions, however, are often subject to dispute (Berdahl, 1942). Ranney (1975) notes that "just about every conflict over making the parties more representative or more democratic or more responsive or more effective turns on the basic question of who should be treated as party members" (p. 145). Some contend that "party members" should be treated synonymously with "party workers," not with "party supporters." Schattschneider (1942), for example, argued: "Whatever else parties may be, they are not associations of voters who support the party candidates. This is to say, the Democratic party is not an association of the twenty-seven million people who voted for Mr. Roosevelt in November, 1940" (pp. 53-54). The McGovern-Frasier Commission (1970), on the other hand, had a much broader definition of party membership than Schattschneider. One of the goals of The Mandate for Reform was to give "all Democratic voters ... a full, meaningful, and timely opportunity to participate" in the selection of party nominees (p. 9).

With the increase in the number of presidential primaries, parties have become, in effect, who votes in a party's primaries or caucuses. Yet who should be allowed to vote in these contests is by no means a simple issue. There have been four basic types of rules governing eligibility to vote in primaries. One allows any registered voter to participate in a primarythe "open" primary. A second allows any registered voter to participate, providing the voter declares his or her partisanship at the polling booth. In a third kind of primary, registered independents may vote in either party's primary, but voters registered with one of the parties are limited to their own party's contest (I refer to this type of system as "semi-closed.)" The last type is one in which only voters registered as members of a party can participate in that party's primary-the so-called "closed" primary. ${ }^{16}$

In recent years the Democratic Party has tried to keep non-Democrats out of its nominating process. The McGovern-Frasier Commission argued

${ }^{15}$ The $50 \%$ cut-off is not just an arbitrary stipulation. In electoral systems using the preference ballot, it is the threshold used for identifying a winner (Lakeman, 1970).

${ }^{16}$ Although this four-way breakdown ignores some differences that exist between states, it nonetheless captures the basic options parties and states can use in determining who can participate in primaries. 
that "a full opportunity for all Democrats to participate is diluted if members of other parties are allowed to participate in the selection of Delegates to the Democratic National Convention" (p. 47). The last two Democratic Party commissions on the nomination process banned "the use of the 'open primary'-a primary in which voters are not required to declare publicly their party preference and to have that preference publicly recorded-to select or allocate delegates to the national conventions" (Manatt, 1982, pp. 12-13). These commission rules, however, still permit registered voters to vote in a primary, provided they "declare publicly" their partisanship.

There has been much speculation that participation in a party's primary by the opposition's partisans adversely affects its selection process. There has, however, been little empirical investigation of this matter. ${ }^{17}$ Using the CBS/ New York Times and ABC/ Washington Post exit polls, I investigated whether independents and members of the opposition's party have different preferences from those of partisans, and how frequently crossover voting occurs.

Table 2 represents preferences of voters for candidates, controlling for partisanship. Independents often prefer different candidates from partisans. In 1976, Ronald Reagan received the support of a higher proportion of independent voters than of Republican voters. Of the nine cases for which I have data, only in New Hampshire and California did Reagan do worse among independents than among Republicans. At times the differences were substantial. In Indiana, the independents and Democrats gave Reagan his margin of victory: among Republicans, Reagan lost $54.5 \%$ to $45.5 \%$ to Ford, but independents gave Reagan a $57.3 \%$ to 42.7\% edge over Ford, and Democrats supported Reagan over Ford $74.6 \%$ to $25.4 \%$. When he sought the Republican nomination in 1980, John Anderson was more popular among Democrats and independents than among members of his own party. Anderson actually won among independent voters in Republican primaries in Massachusetts, Wisconsin and Illinois, though he did not win any of these contests.

In Democratic primaries, independents did not differ consistently from Democratic identifiers. In New Hampshire in 1976, Morris Udall finished first among Democratic identifiers, while among independents and Republicans Carter won. In Wisconsin and Michigan Udall won among independents, though he lost the primary. In the 1980 Kennedy-Carter race, there was no consistent beneficiary of independents' support. In 1980 Governor Brown did better among independents than Democrats, but this performance still could not make him a serious challenger. 
TABLE 2

Voter's Preferences by Partisanship

\begin{tabular}{|c|c|c|c|}
\hline & RePublicans & INDEPENDENTS & DEMOCRATS \\
\hline \multicolumn{4}{|c|}{ Democrats, 1976} \\
\hline Carter $(n=10)$ & $40.2 \%$ & $36.6 \%$ & $38.5 \%$ \\
\hline Udall $(n=6)$ & $19.4 \%$ & $29.2 \%$ & $27.2 \%$ \\
\hline Jackson $(n=5)$ & $23.8 \%$ & $16.3 \%$ & $19.0 \%$ \\
\hline Wallace $(n=7)$ & $19.6 \%$ & $15.5 \%$ & $16.5 \%$ \\
\hline \multicolumn{4}{|c|}{ Republicans, 1976} \\
\hline Ford $(n=9)$ & $58.0 \%$ & $48.8 \%$ & $49.1 \%$ \\
\hline Reagan $(n=9)$ & $42.0 \%$ & $51.2 \%$ & $50.9 \%$ \\
\hline \multicolumn{4}{|c|}{ Democrats, 1980} \\
\hline Brown $(n=5)$ & $8.6 \%$ & $11.1 \%$ & $6.3 \%$ \\
\hline Carter $(n=9)$ & $57.2 \%$ & $44.4 \%$ & $50.4 \%$ \\
\hline Kennedy $(n=9)$ & $27.5 \%$ & $42.0 \%$ & $44.3 \%$ \\
\hline \multicolumn{4}{|c|}{ Republicans, 1980} \\
\hline Anderson $(n=5)$ & $16.0 \%$ & $31.5 \%$ & $41.3 \%$ \\
\hline Reagan $(n=8)$ & $58.7 \%$ & $43.9 \%$ & $41.8 \%$ \\
\hline Bush $(n=8)$ & $26.2 \%$ & $30.3 \%$ & $27.1 \%$ \\
\hline
\end{tabular}

Percentages are the average share of the vote each candidate received in the relevant primaries.

Source: CBS/New York Times Poll

ABC/Washington Post Polls.

There is little doubt that independents can alter the outcome of primary elections. But even in closed primaries, in which only party members are supposed to participate, self-identified independents and partisans of the opposition party still constitute a sizable segment of the electorate (see table 3). Differing requirements for voting do not appear to have a large effect on the composition of primary electorates. ${ }^{18}$ Among closed Democratic primaries $72.6 \%$ of the electorate labeled themselves Democrats. In semi-closed contests this proportion declines only to 68.8\%. ${ }^{19}$ For open contests the proportion is $65.1 \%$. The Republican figures

18 The likely reason that these rules have only a limited effect on the partisan composition of the electorate is that they do not act as major barriers to participation. To vote, for instance, in a closed primary, all a voter has to do is register with the party. And this act does not provide reliable information about true partisanship (Ranney, 1978, p. 221). Thus, while the closed primary provides more barriers to participation than these other three rules, it is still not enough of a barrier to prevent crossover voting.

${ }^{19}$ There were two surveys in which the partisanship question was not used. Instead a question concerning party registration was used. When these cases are eliminated, the difference becomes $71.8 \%$ to $67.8 \%$, not a major difference. 
tell a similar story, though in the case of open primaries more nonRepublican voters participated. The figures are $73.8 \%, 66.7 \%$, and $51.5 \%$ for closed, semi-closed, and open, respectively. In the $1980 \mathrm{Wisconsin}$ Republican primary, $57.5 \%$ of the electorate were either Democrats or Independents-the highest proportion of non-partisans among all the states. This high proportion of non-Republicans was surely due, in part, to Anderson's appeal to independents and Democrats.

TABle 3

The Partisan Make-up of the Electorate in Primaries under Different Rules

\begin{tabular}{|c|c|c|c|}
\hline & Republicans & INDEPENDENTS & DEMOCRATS \\
\hline \multicolumn{4}{|c|}{ Democrats } \\
\hline Open $(n=3)$ & $6.3 \%$ & $28.6 \%$ & $65.1 \%$ \\
\hline Closed $(n=6)$ & $4.4 \%$ & $23.8 \%$ & $72.6 \%$ \\
\hline Semi-closed $(n=5)$ & $2.8 \%$ & $28.4 \%$ & $68.8 \%$ \\
\hline Declare Polls ${ }^{*}(n=5)$ & $5.0 \%$ & $25.2 \%$ & $69.9 \%$ \\
\hline \multicolumn{4}{|c|}{ Republicans } \\
\hline Open $(n=4)$ & $51.5 \%$ & $36.6 \%$ & $12.0 \%$ \\
\hline Closed $(n=4)$ & $73.8 \%$ & $22.6 \%$ & $3.6 \%$ \\
\hline Semi-closed $(n=5)$ & $66.7 \%$ & $29.6 \%$ & $3.7 \%$ \\
\hline Declare Polls ${ }^{\circ}(n=4)$ & $69.1 \%$ & $26.3 \%$ & $4.6 \%$ \\
\hline
\end{tabular}

These data are an average of the partisan breakdown in each type of primary in 1976 and 1980.

Source: CBS/New York Times Poll ABC/Washington Post Polls.

-These are primaries in which voters must declare they are partisans of a party in order to vote in that party's primary.

Even if it were possible to close the nominating process so that only partisans could vote, would it be desirable? If one wants primaries to nominate highly electable candidates, an argument can be made for allowing independents and partisans from the opposition's party to participate in primaries. When choosing a candidate in the now-defunct mixed system, party leaders typically sought a candidate who could win the support not only from their partisans, but also from independents and weak partisans of the other party. V.O. Key (1964) contended that "each 
party leadership must maintain the loyalty of its own standpatters; it must also concern itself with the great block of voters uncommitted to either party as well as those who may be weaned away from the opposition." Eisenhower's nomination in 1952 can be largely attributed to the belief of many Republican delegates that he could attract independent and Democratic support that Taft could not. Since now neither party constitutes a majority of the electorate, winning the general election requires a candidate to gain votes from citizens who do not identify with that party. Certainly the Republican success in recent presidential elections can be attributed to that party's ability to attract independents and defectors from the Democratic party.

So if parties want to nominate electable candidates and they use primaries to choose electable nominees, there are good reasons for making certain that the candidates they select are attractive to independents and opposition party voters. It is unlikely that independents would "raid" a party's primary to vote for their least favorite candidate to undermine that party's chances in the general election. A more likely reason for independents (or even partisans of the other party) to vote in a partisan primary is that they found a candidate they would be willing to support in November. Certainly the support Anderson and Wallace received from outside their own party is consistent with this argument. Overacker (1926) came to a similar conclusion in her study of presidential primaries: "A careful study of the cases where the members of one party have participated in the primary of the other party . . . lends no color to the claim of the opponents of the 'open' primary that voters go into the opposing party to throw their vote to the weakest candidates, or the candidates whom they think will be the most easily beaten in the election. In every case they have been motivated by a genuine interest in, and support of, the candidate for whom they voted" (p. 98).

In short, political parties should not worry about trying to limit participation only to partisans. It is in the interest of parties to encourage independents and potential defectors from the other party to participate in its primary, since knowing the preferences of these "swing" voters is useful when trying to select a nominee who has broad support. Thus, the last change in the rules I am advocating is to have the state parties adopt either an "open" primary or "declare at polls" primary. ${ }^{20}$

${ }^{20}$ One might argue, given the evidence in table 3 , that changing the rules would have little influence on the partisan composition of primary electorates. While it is true that it may not always make a large difference, there is at least the potential for all registered voters to participate in a primary if they happened to be motivated by a particular candidate. Consequently, if a candidate has a great deal of support outside of the party, there would be an opportunity for it to be expressed. 


\section{ConClusion}

As we have seen, the current primary system does not provide good information about a candidate's potential popularity for the general election. If the parties want to nominate candidates with broad support, then they should allow independents and weak partisans of the opposing party to participate in primaries, use a proportional representation scheme to allocate delegates, and adopt a preference ballot. Adopting such reforms, however, is not without potential drawbacks, because knowing voters' preferences may not automatically lead to nominating candidates who are capable of winning in November. For instance, these rules may foster hard fought multi-candidate campaigns, which could divide the party so seriously that the fall election would be nearly impossible to win. ${ }^{21}$ Thus, while the parties may be getting a better indicator of a candidate's popularity, these reforms could have exactly the opposite effect from the one intended. There is a growing literature assessing whether divisive primaries hinder a party's chance for victory in the general election (see Pierson and Smith, 1975; Bernstein, 1977; Lengle, 1980; Born, 1981; Kenney and Rice, 1984, 1985; and Westlye, 1985).

While divisiveness is a real concern, it should not serve as a major obstacle to nominating highly electable candidates through my "reformed" primary system. First, the literature on the effect of divisive primaries on general election results is mixed (Kenney and Rice, 1984, p. 905). And in those studies that have found divisiveness to be detrimental to the party's chances in the fall election, the effect has been small (Born, 1981; Kenney and Rice, 1985). The reason for these small, and often conflicting, results may be simply that strong candidates do not face stiff nomination struggles because potential rivals, seeing the popularity of their opponent, decide against running, while weak candidates often have divisive primaries and lose in November, because their vulnerability invites challenges from within their party. Thus, divisiveness per se may have little, if any, impact beyond the effect of the prior strength of the candidates (Born, 1981; and Westlye, 1985).

${ }^{21}$ There are, of course, other problems that might arise from my rules. Allowing independents and opposing partisans to participate, for example, may be seen by loyal partisans as undercutting the values of the party. If disillusioned, the "core" party supporters might be less willing to work for the party and contribute money to its campaign treasury. But I suspect that core partisans would not react in such a way. If the nominee has a good chance of being electable, these core supporters might be more willing to help the nominee, since one generally prefers to back a winner.

Another problem is that a preference ballot could confuse voters (especially the poorly educated ones) and lessen turnout in the short run, leading potentially to primary electorates that are highly unrepresentative of the rank and file selecting the nominee. This concern is reasonable and efforts would have to be made to educate the public about this change.

These potential problems are not, however, as important as the possible effects of divisiveness, since it has direct implications for nominating electable candidates. 
Second, there is little reason to think my specific reforms would exacerbate the problem of divisiveness in presidential primaries. The proportional representation rule, for example, could keep contenders in the race longer than a system that favors the winner of a primary, which could be harmful to party unity by dragging out the length of the struggle. Yet, with the possible exception of Jesse Jackson, candidates, if anything, tend to drop out of the race too quickly. The winnowing process, rather than the rules allocating delegates, is largely responsible for cutting down the number of active candidates. Moreover, the divisiveness that does exist in presidential primaries is probably more due to the long primary season and the numerous opportunities for the candidates to exchange barbs than the rule I am advocating. In recent years there have been a number of hard-fought campaigns, such as the ones between Reagan and Ford in 1976, Kennedy and Carter in 1980, and Hart and Mondale in 1984. It seems unlikely that my rules would have increased the bitterness that existed between these rivals.

The chances of divisiveness may actually be somewhat reduced under my proposed arrangement. The reformed primary system would allocate delegates in proportion to the candidate's share of the vote while using a preference ballot. This combination of rules may help reduce the possibility of hard-fought, multi-candidate primaries. First, and perhaps most important, my rules would prevent candidates who have narrow bases of support from winning primaries, because a candidate must have at least some support among $50 \%$ of the electorate. Without the resulting media attention and extra delegates accorded a winner, such candidates may be less willing (and less able) to carry out a protracted battle for the nomination. Second, my proposed system would provide few, if any, delegates to the distant finishers, because when no candidate receives $50 \%$ of the vote the preference ballot eliminates the candidate with the fewest votes. Thus, the rules may encourage candidates with little support to withdraw (and may even discourage these type of candidates from undertaking their long-shot campaigns), since they would be securing so few delegates. The remaining candidates may be locked in a competitive and possibly divisive struggle, but no more so than have been recent contenders for the nomination. Finally, since these rules attempt to reflect each candidate's popularity and are not designed to favor specific candidates, ${ }^{22}$ there may be fewer battles over the rules, as we saw in the 1984 Democratic nomination.

Contrary to conventional wisdom, primaries can offer political parties the opportunity to nominate candidates with broad support, providing the rules governing them are designed to reflect more faithfully the

\footnotetext{
${ }^{22}$ While, of course, certain kinds of candidates will be helped under my system, the rules were not written explicitly to favor a specific candidate, as has been the case in recent years.
} 
preferences-including second preferences-of both regular party voters and potential party supporters. Party leaders in the "mixed system" did use primaries as indicators of a candidate's electability. John Kennedy's victory over Hubert Humphrey in the 1960 West Virginia primary is probably the most famous case in which the results of a primary were taken as an indication of a candidate's electability. The irony is that with the proliferation of primaries, party leaders have not seized on the opportunity to use primaries in the manner I have advocated.

\section{REFERENCES}

Adamany, David. 1976. Crossover Voting and the Democratic Party's Reform Rules. American Political Science Review, 70: 536-41.

$\rightarrow$ Berdahl, C. 1942. Party Membership in the United States. American Political Science Review, 36: 16-50, 241-62.

Bernstein, Robert A. 1977. Divisive Primaries Do Hurt: U.S. Senate Races, 1956-1972. American Political Science Review, 71: 540-45.

Black, Duncan. 1958. The Theory of Committees and Elections. Cambridge: Cambridge University Press.

$\rightarrow$ Born, Richard. 1981. The Influence of House Primary Election Divisiveness on General Election Margins, 1962-1976. Journal of Politics, 43: 640-61.

Brams, Steven, and Peter C. Fishburn. 1983. Approval Voting. Boston: Birkhauser.

Ceasar, James W. 1979. Presidential Selection: Theory and Development. Princeton: Princeton University Press. 1982. Reforming the Reforms. Cambridge, MA: Ballinger.

David, Paul T., and James W. Ceaser. 1980. Proportional Representation in the Presidential Nominating Process. Charlottesville: University Press of Virginia.

DeMaio, Gerald, and Douglas Muzzio. 1981. The 1980 Elections and Approval Voting. Presidential Studies Quarterly, 11: 364-73.

Downs, Anthony. 1957. An Economic Theory of Democracy. New York: Harper and Row.

$\rightarrow$ Hammond, Jack H. 1980. Another Look at the Role of 'The Rules' in the 1972 Democratic Presidential Primaries. Western Political Quarterly, 33: 50-72.

$\rightarrow$ Hedlund, R.D. 1977-1978. Cross-over Voting in a 1976 Open Presidential Primary. Public Opinion Quarterly, 41: 498-514.

Hedlund, R.D., Meredith W. Watts, David M. Hedge. 1982. Voting in an Open Primary. American Politics Quarterly, 10: 197-218.

Joslyn, Richard A. 1976. The Impact of Decision Rules in Multi-Candidate Campaigns: The Case of the 1972 Democratic Nomination. Public Choice, 25: 1-17.

Kellet, John, and Kenneth Mott. 1977. Presidential Primaries: Measuring Popular Choice. Polity, 9: 528-37.

$\rightarrow$ Kenney, Patrick J., and Tom W. Rice. 1984. The Effect of Primary Divisiveness in Gubernatorial and Senatorial Elections. Journal of Politics, 46: 904-15.

1985. The Effects of Primary Divisiveness in Presidential Elections. Paper presented at the annual meeting of the American Political Science Association, New Orleans.

Key, V.O. 1964. Politics, Parties, and Pressure Groups. New York: Thomas Y. Cromwell, 5 th ed.

Lakeman, Enid. 1970. How Democracies Vote. London: Faber and Faber.

$\rightarrow$ Lengle, James I. 1980. Divisive Presidential Primaries and Party Electoral Prospects, 19321976. American Politics Quarterly, 8: 261-77. 
Lengle, James I., and Bryon E. Shafer. 1976. Primary Rules, Political Power, and Social Change. American Political Science Review, 70: 25-40.

McGovern, George, and Donald Fraser. 1970. Commission on Party Structure and Delegate Selection. Mandate for Reform. Washington, DC: Democratic National Committee.

Manatt, Charles T. 1982. Commission on Presidential Nomination. The Report of the Commission on Presidential Nomination. Washington, DC: Democratic National Committee.

Mueller, Dennis. 1979. Public Choice. Cambridge: Cambridge University Press.

Niemi, Richard G. 1984. The Problem of Strategic Behavior under Approval Voting. American Political Science Review, 78: 952-58.

$\rightarrow$ Niemi, Richard G., and Larry M. Bartels. 1984. The Responsiveness of Approval Voting to Political Circumstances. PS, 17: 571-76.

Ostrogorski, M. 1902. Democracy and the Organization of Political Parties. New York: MacMillian.

Overacker, Louise. 1926. The Presidential Primary. New York: MacMillian.

Pierson, James E., and Terry B. Smith. 1975. Primary Divisiveness and General Election Success: A Reexamintion. Journal of Politics, 37: 555-62.

$\rightarrow$ Polsby, Nelson W. 1960. Decision-Making at the National Conventions. Western Political Quarterly, 13: 609-19.

1983. Consequences of Party Reform. Cambridge: Oxford University Press.

Pomper, Gerald. 1979. New Rules and New Games in Presidential Nominations. Journal of Politics, 41: 784-805.

Rae, Douglas. 1967. The Political Consequences of Election Laws. New Haven: Yale University Press.

Ranney, Austin. 1975. Curing the Mischiefs of Faction: Party Reform in America. Berkeley: University of California Press.

. 1978. Changing the Rules of the Presidential Nominating Game. In Jeff Fishel, ed., Parties and Elections. Bloomington, IN: Indiana University Press.

Schattschneider, E.E. 1942. Party Government. New York: Holt, Rinehart \& Winston.

Tufte, Edward. 1973. The Relationship between Seats and Votes in Two Party Systems. American Political Science Review, 67: 540-54.

Westlye, Mark C. 1985. The Effects of Primary Divisiveness on Incumbent Senators, 19681984. Paper presented at the annual meeting of the American Political Science Association, New Orleans. 